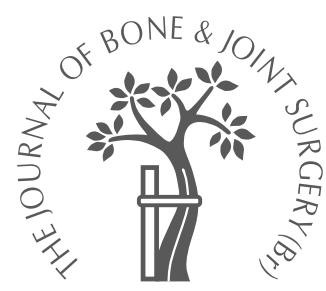

- ANNOTATION

\title{
Mechanical muscle-crush injury and acute muscle-crush compartment syndrome
}

\author{
WITH SPECIAL REFERENCE TO EARTHQUAKE CASUALTIES
}

\begin{abstract}
N. D. Reis, O. S. Better
\end{abstract}

From the Faculty of Medicine, Technion, Israel Institute of Technology and the Ramban Medical Centre, Haifa, Israel

N. D. Reis, FRCSE, Emeritus Associate Clinical Professor of Orthopaedic Surgery

Horev Medical Centre, 15 Horev Street, Haifa, 34341, Israel.

O.S. Better, MD, Emeritus Professor of Medicine

The Michael and Helen Schaffer Centre for Research in Military Medicine,

Faculty of Medicine,

Technion, Israel Institute of

Technology, Rappaport

Family Medical Science

Building, Bat Galim, P.O. Box

9649, Haifa, 31096, Israel.

Correspondence should be sent to Professor N. D. Reis; e-mail:

ioanaor@netvision.net.il

(C2005 British Editorial

Society of Bone and

Joint Surgery

doi:10.1302/0301-620X.87B4.

$15334 \$ 2.00$

$J$ Bone Joint Surg $[\mathrm{Br}]$

2005;87-B:450-3.
An extensive muscle-crush injury culminating in a crush syndrome is often lethal unless treated actively and promptly. The causes of death in crush syndrome include hypovolaemic shock, hyperkalaemia, hypocalcaemia, metabolic acidosis, acute myoglobinuric renal failure and the acute muscle-crush compartment syndrome.

The incidence of crush syndrome after major earthquakes, which often occur in remote regions, depends upon the unique nature, location and timing of each disaster. It has been estimated that between $2 \%$ and $5 \%$ of the injured will suffer from crush syndrome as reported for the Tangshan earthquake (242 769 dead and 164851 injured). ${ }^{1}$ After the collapse of a multi-storey building, $80 \%$ of its occupants will be killed instantly and $20 \%$ may be extricated alive if this is achieved within 24 hours. ${ }^{2}$ However, approximately $40 \%$ of the survivors will suffer from the crush syndrome. Early death of extricated survivors is caused by shock and/or hyperkalaemia, whereas late death is caused by myoglobinuric acute renal failure and/or sepsis.

During the last 30 years we have had the opportunity of studying mechanical musclecrush injury (MMCI) and its consequences, resulting from the entrapment of casualties under collapsed buildings. Our hospital has been the major trauma centre serving a chronic war zone catchment area, including the south Lebanon theatre, in which periodic flare-ups of war and terror have provided a recurrent source of crushing injuries. Furthermore, as consultants to the Rescue and Extrication Unit of the Israel Defence Forces, we have had the benefit of sharing this unit's unique experiences. After an alert, this unit can be scrambled on to a Hercules transport aircraft in less than 24 hours and has succeeded in reaching several overseas earthquake disaster areas in sufficient time to undertake useful work. Orthopaedic surgeons throughout the world are frequently involved in the treatment of such casualties and yet may be unfamiliar with the accumu- lated world experience of the results of the treatment of MMCI. The purpose of this review is to summarise critically our own experience and that gleaned from the international literature.

\section{History of $\mathrm{MMCl}$}

According to Howse and Seddon, ${ }^{3}$ Larrey, a Napoleonic Army surgeon, described MMCI in 1812 in a comatose soldier poisoned by carbon monoxide, who developed muscle and skin necrosis in areas of the body which had been exposed to static, prolonged gravitational pressure.

Bywaters, ${ }^{4}$ reported in a retrospective review, that von Colmers had described traumatic muscle destruction in the Messina earthquake of 1909. Frankenthal, ${ }^{5}$ described MMCI in 1916 associated with acute renal failure in victims buried alive during the First World War. Bywaters' pioneering work in the London Blitz (1941) was the first report of MMCI as the cause of acute renal failure in the English language literature. ${ }^{6,7}$ He subsequently studied an experimental model ${ }^{8}$ and reviewed MMCI in its various aspects, ${ }^{9}$ establishing the basic principles of treatment using early, massive transfusion of fluids with alkalinisation of the urine.

Trueta et $\mathrm{al}^{10}$ had previously studied acute renal failure after crushing injury during the aerial bombardment of Barcelona during the Spanish Civil War (1936-9) and published his work in 1943, having moved to Oxford.

\section{Acute muscle-crush compartment syndrome}

Pathology and pathophysiology. Muscle can survive circulatory ischaemia for up to four hours. Violent crushing destroys muscle immediately; even if the force is insufficient to mangle the muscle tissue, the combination of mechanical force and ischaemia will cause muscle death within an hour. Any intramuscular mechanical force which acts continually above the diastolic blood pressure causes this combination. ${ }^{11}$ 
Table I. Recommended volume replacement during and after extrication of an otherwise healthy, adult casualty with $\mathrm{MMCl}^{*}$ adapted from Ron et al ${ }^{35}$

1. While the limb is being extricated immediately start intravenous saline at a rate of one litre per hour (the extrication stage may last many hours). Monitor arterial pressure, central venous pressure and urinary output as soon as possible

2. After extrication, continue intravenous infusion with $500 \mathrm{ml}$ normal saline alternating with $500 \mathrm{ml} 5 \% \mathrm{glucose}$ at a rate of one litre per hour

3. On admission to hospital add $50 \mathrm{mEql}$ of sodium bicarbonate to each second or third bottle of glucose in order to maintain the urinary pH $>6.5$

4. Once the urine flow is established, add $20 \%$ mannitol solution at a rate of 1 to $2 \mathrm{~g} / \mathrm{kg}$ estimated body weight over about four hours. Never exceed $200 \mathrm{~g}$ per day and never administer mannitol in the presence of established anuria

5. Optimal urine flow is 8 litres per day. This will require an infusion of 12 litres per day. This positive balance is largely explained by the limb oedema in the crush region, and is permissable when the kidneys are at risk

6. If bicarbonate has produced a metabolic alkolosis (arterial pH of 7.45) acetazolamide is given intravenously as a 500 mg bolus

7. This regimen is continued until myoglobin has disappeared from the urine, usually by the third day

${ }^{*} \mathrm{MMCl}$, mechanical muscle-crush injury

This form of acute rhabdomyonecrosis is familiar to spine surgeons in prolonged operations when the patient is positioned in the praying mantis position, ${ }^{12}$ and to casualty officers admitting drug addicts who have been lying unconscious in one position without moving for many hours. ${ }^{13}$

External mechanical pressure destroys the volume regulation of myocytes, whose cytoplasm is negatively charged and is hyperosmotic compared with the extracellular fluid. By disrupting the impermeability of the sarcolemma, extracellular cations and fluid flow down the electrochemical gradient into sarcoplasm, overwhelming the capacity of the cationic extrusion pumps ${ }^{14-18}$ and leading to swelling of the myocytes. Consequently, MMCI causes such gross oedema that it may incarcerate much of the extracellular fluid and cause hypovolaemic shock within hours of injury. ${ }^{2}$ The local manifestation is acute muscle-crush compartment syndrome, which develops rapidly in and around the crushed muscle, as a reperfusion syndrome, and which appears immediately after the extrication of a trapped victim and the consequent removal of the crushing force. An ominous chain of events then unfolds as the crushed vasculature allows the rapid seepage of fluid and plasma proteins into the dead muscle that is sheathed within its inelastic fascial compartment. A hyperperfusion rebound phenomenon in the dead muscle may also be involved. ${ }^{2}$ We have always observed that crushed, dead muscle bleeds profusely. ${ }^{19}$

When a victim is rescued he or she may be dehydrated as the rapid loss of fluid into the compartment may tip the balance into profound, hypovolaemic shock. In addition intracellular potassium ions released through the incompetent sarcolemma of the dead muscle cells surge into the general circulation at this reperfusion stage and set the stage for sudden hyperkalaemic cardiac arrest. This can occur very rapidly, as soon as two hours after extrication. ${ }^{2}$ Also, at this stage nephrotoxic myoglobin released from the disrupted muscle cells floods the circulation, creating the possibility of acute renal failure. Prolonged crushing of the torso leads to death so that those injuries which come to treatment almost exclusively involve the limbs.

Diagnosis. The diagnosis is usually obvious if the history is known and the limb is inspected. MMCI is not usually painful immediately after extrication and the limb is often numb with a peripheral pulse that is almost universally present if the patient is not in shock. Direct arterial injury is very rare in closed MMCI. Swelling appears rapidly, causing an acute compartment syndrome and within hours the limb can become turgid and brawny without obstruction to the distal circulation. The crushed skin is bruised and discoloured but remains intact. Pain develops gradually and may become excruciating. Intracompartmental pressure can be measured by intramuscular manometry as described by Whitesides et $\mathrm{al}^{20}$ in 1975 and Hargens and Mubarak ${ }^{21}$ in 1981. Although the clinical picture is clear-cut we know of cases, which have been diagnosed as thrombophlebitis or paraplegia. ${ }^{19}$ These patients were unable to give a history of being crushed having been admitted in a confusional state.

\section{Management}

General. A nephrologist is not always immediately available, so the orthopaedic surgeon should have some knowledge of the fluid requirements which are indicated in the early, emergency situation (Table I).

In order to counter both the life-threatening hyperkalaemia and hypocalcaemia, and to prevent myoglobinaemia from causing acute renal failure, massive fluid transfusion and alkalinisation of the urine must be begun as early as possible. We have published the protocol for this as well as our recommended indications and contraindications for the use of mannitol. ${ }^{22}$ Massive infusion must be commenced as soon as intravenous access has been obtained even while the victim is still trapped..$^{23}$ The sooner fluid replacement is established the better the chance of avoiding renal failure. ${ }^{23}$

Intraosseous transfusion may also be considered in future should the intravenous route be inaccessible although our own experience to date with this technique is limited.

Local. The classical management of an acute compartment syndrome has recently been reviewed; ${ }^{24}$ an immediate fasciotomy is performed in order to achieve decompression, thereby improving both local and distal blood supply. However, there are dangers to this treatment as compartment syndrome usually follows a closed injury. By creating an open wound, profuse bleeding may occur, aggravating coagulopathy and complicating dialysis for myoglobinuric acute renal failure. Life- or limb-threatening sepsis is a real risk. ${ }^{19,25}$ Dead, crushed muscle bleeds abundantly, is deceptively normal in appearance, and can only be differentiated 
from healthy muscle by its lack of contractility on electrical stimulation. ${ }^{19}$ Excision of necrotic muscle is inevitably incomplete and must be repeated, often several times, under general anaesthesia. If many fasciotomies have been performed in an earthquake disaster zone the queue of patients requiring further excision compete for scarce operating theatre time and present a logistic problem. Acute muscle crush compartment syndrome differs from other forms of compartment syndrome, in which at-risk muscle can be saved by fasciotomy because in acute muscle crush compartment syndrome the muscle is already dead. Worldwide experience has shown that the theoretical benefits of a fasciotomy in these circumstances are far outweighed by its hazards. We first reported this following our experience in $1982 .{ }^{19}$ Further reports subsequently appeared from Iran, ${ }^{26}$ Japan $^{27}$ and Turkey. ${ }^{25}$

The review by Sever et $\mathrm{al}^{25}$ of 379 fasciotomies performed during the Turkish Marmara earthquake showed that the rate of fasciotomy was related to sepsis and sepsis to mortality. The authors concluded that fasciotomy was usually contraindicated. Unfortunately the lesson was not learned. Following a further, catastrophic earthquake at Bingol, Turkey, in 2003, routine fasciotomies were performed in almost $70 \%$ of the patients with acute muscle crush compartment syndrome, $81 \%$ of whom subsequently developed wound sepsis. ${ }^{28}$ Tetsuya et $\mathrm{al}^{27}$ reviewed the results of the treatment of crushing injuries in the 1995 Hanshin-Awaji earthquake and concluded that there was no evidence that fasciotomy improved the late outcome. Huang et al, ${ }^{29}$ describing patients who were injured in the earthquake at Chi-Chi in China and Nadjafi et $a^{26}$ those injured in Iran in 1977, came to similar conclusions. In our study we had compared two similar groups of crush injuries. One had undergone a routine fasciotomy with a high rate of sepsis and amputation while the other had been treated conservatively with no sepsis and no amputations. ${ }^{19}$ To date, in the past 35 years we have treated 31 cases of acute muscle crush compartment syndrome. Since adopting a conservative protocol in 1982, no closed crush injury has developed life-threatening sepsis and no urgent amputations have been required. A patient with a poor functional result following acute compartment syndrome in a crushed limb will require subsequent reconstructive procedures such as tendon lengthening, osteotomy, arthrodesis, or even a late, definitive amputation, in order to improve function. Fasciotomy is recommended within six hours of the development of a compartment syndrome ${ }^{24}$ but it is not indicated when the muscle is already dead, a situation which invariably exists in acute muscle crush compartment syndrome. There is, in our opinion, no place for prophylactic fasciotomy.

In view of the evidence that has accumulated it can now be categorically stated that fasciotomy is contraindicated in patients with closed acute muscle crush compartment syndrome. It does not improve the outcome for the limb, nor for the kidneys. Fasciotomy under these circumstances endangers life and limb. The only indication for fasciotomy is when the distal pulse is absent and when both direct, major arterial injury and systemic hypotension have been excluded.

Pressure can be reduced without invading the compartment and risking infection, by the use of the intravenous hypertonic mannitol, ${ }^{22,30}$ although this is strictly contraindicated in the presence of renal failure. The use of mannitol as a decompressive agent has been reviewed by Better et al. $^{31}$

A further form of conservative treatment is hyperbaric oxygenation. This specifically reduces oedema and floods the tissues with oxygen dissolved in the extracellular fluid. This oxygen is available to the compromised cells without the energy expenditure otherwise required for its transfer from haemoglobin. ${ }^{32}$ Strauss and Hart ${ }^{33}$ noted, in a series of patients with compartment syndrome who were treated with hyperbaric oxygen, that none progressed and none required a fasciotomy. Our experience with hyperbaric oxygenation has been similar but, in common with Strauss and Hart, ${ }^{33}$ we have no specific experience with hyperbaric oxygenation in the treatment of acute muscle crush compartment syndrome. However, the rationale for using hyperbaric oxygenation is overwhelmingly persuasive ${ }^{34}$ and we intend to explore this treatment in future for sporadic cases. In an earthquake scenario, hyperboric oxygenation is unlikely to be available.

Orthopaedic treatment should, therefore, be primarily conservative. Joints are splinted in a functional position, while active and passive movements are encouraged as soon as pain allows. Finally, ischaemic muscle contractures and paralysis caused by the destruction of muscle are corrected by late reconstructive surgery.

When MMCI is open, the treatment is the same as any severe, open wound; radical debridement, repeated as necessary, which may also require the opening of fasciae and extension of the wound in order to remove all dead tissue and achieve adequate drainage. These principles do not apply to a patient with closed acute muscle crush compartment syndrome.

\section{References}

1. Sheng Z-Y. Medical support in the Tangshan earthquake: a review of the management of mass casualties and certain major injuries. J Trauma 1987;21:1130-4.

2. Better OS, Stein JH. Early management of shock and acute renal failure in traumatic rhabdomyolysis. N Eng J Med 1990;322:825-9.

3. Howse AJG, Seddon H. Ischaemic contracture of muscle associated with carbon monoxide and barbiturate poisoning. Br Med J 1966;548:192-5.

4. Bywaters EGL. 50 years on: the crush syndrome. Br Med J 1990;301:1412-15.

5. Frankenthal L. Ueber Verschuettungen. Virchows Archives 1916;22:332-45 (in German).

6. Bywaters EGL, Beal D. Crush injuries with impairment of renal function. Br Med J $1941 ; 1: 427-32$.

7. Bywaters EGL, Delory GE, Rimington C, Smiles J. Myohaemoglobin in air raid casualties with crushing injury. Biochem J 1941;35:1164-8.

8. Bywaters EGL, Popjak G. Experimental crushing injury. Surg Gynecol Obstet 1942; 75:612-27.

9. Bywaters EGL. Ischaemic muscle necrosis. JAMA 1944;124:1103-9.

10. Trueta J, Barclay AE, Daniel PM, Franklin KJ, Prichard MML. Studies of the renal circulation. Oxford: Blackwell Scientific Publications, 1947:67-126. 
11. Heppenstall RB, Scott R, Sapega A, Park YS, Chance B. A comparative study of the tolerance of skeletal muscle to ischaemia: tourniquet application compared with acute compartment syndrome. J Bone Joint Surg [Am] 1986;68-A:820-8.

12. Foster MR. Rhabdomyolysis in lumbar spine surgery: a case report. Spine 2003;28 276-8.

13. Richards JR. Rhabdomyolysis and drugs of abuse. J Emerg Med 2000;19:51-6.

14. Rubinstein I, Abassi Z, Coleman R, et al. Involvement of nitric oxide system in experimental muscle crush injury. J Clin Invest 1998;101:1325-33.

15. Leaf A. Maintenance of concentration gradients and regulation of cell volume. Ann $N$ Y Acad Sci 1959;72:396-404.

16. Guharay F, Sachs F. Stretch-activated single ion channel currents in tissue cultured embryonic chick skeletal muscle. J Physio/ 1984;352:685-701.

17. Christensen $\mathbf{0}$. Mediation of cell volume regulation by $\mathrm{Ca} 2+$ influx through stretch activated channels. Nature 1987;330:66-8.

18. Better OS, Abassi Z, Rubinstein I, et al. The mechanism of muscle injury in crush syndrome: ischaemic versus pressure-stretch myopathy. Miner Electrolyte Metab 1990;16:181-4.

19. Reis ND, Michaelson M. Crush injury to the lower limbs: treatment of the local injury. J Bone Joint Surg [Am] 1986;68-A:414-18.

20. Whitesides TE, Haney TC, Moromoto K, Harada H. Tissue pressure measurements as a determinant for the need of fasciotomy. Clin Orthop 1975;113:43-51.

21. Hargens AR, Mubarak SJ. Laboratory diagnosis of acute compartment syndrome In: Mubarak SJ, Hargens AR, eds. Compartment syndrome and Volkman's contracture. Philadelphia: W. B. Saunders Co, 1981:106-22.

22. Better OS. Rescue and salvage of casualties suffering from the crush syndrome after mass disasters. Mil Med 1999;164:366-9.

23. Better OS, Rubinstein I, Reis ND. Muscle crush compartment syndrome: fulminant local oedema with threatening systemic effects. Kid Int 2003;63:1155-7.
24. Elliott KGB, Johnstone AJ. Diagnosing acute compartment syndrome. J Bone Joint Surg [Br] 2003;85-B:625-32.

25. Sever SM, Erek E, Vanholder R, et al. Clinical findings in the renal victims of a catastrophic disaster: the Marmara earthquake. Nephrol Dial Transplant 2002;17: 1942-9.

26. Nadjafi I, Atef MR, Broumand B, Rastegar A. Suggested guidelines for treatment of acute renal failure in earthquake victims. Ren Fail 1997; 19:655-64.

27. Tetsuya M, Toshiharu Y, Hiroshi T, et al. Long term physical outcome of patients who suffered crush syndrome after the 1995 Hanshin-Awaji earthquake: prognostic indicators in retrospect. J Trauma 2002;52:33-9

28. Gunal Al, Celiker H, Dogukan A, et al. Early and vigorous fluid resuscitation prevents acute renal failure in the crush victims of catastrophic earthquakes. J Am Soc Nephro/ 2004;15:1862-7.

29. Huang KC, Lee TS, Lin YM, Shu KH. Clinical features and outcome of crush syndrome caused by the Chi-Chi earthquake. J Formos Med Assoc 2002;101:249-56.

30. Gold BS, Barish RA, Dart RC, Silverman RP, Bochicchio GV. Resolution of compartment syndrome after rattlesnake envenomation utilizing non-invasive methods. J Emerg Med 2003;24:285-8.

31. Better 0, Rubinstein I, Winaver JM, Knochel JP. Mannitol therapy revisited (1940-1997). Kidney Int 1997;51:886-94.

32. Skyhar MJ, Hargens AR, Strauss MB, et al. Hyperbaric oxygen reduces edema and necrosis of skeletal muscle in compartment syndromes associated with haemorrhagic hypotension. J Bone Joint Surg [Am]1986;68-A:1218-24.

33. Strauss MB, Hart GB. Hyperbaric oxygen and the skeletal muscle compartment syndrome. Contemporary Orthopaedics 1989;18:167-74.

34. Strauss MB, Hart GB. Crush injury and the role of hyperbaric oxygen. Topics in Emergency Med 1984;6:9-24.

35. Ron D, Taitelman U, Michaelson M, et al. Prevention of acute renal failure in traumatic Rhabdomyolysis. Arch Intern Med 1986:144:277-80. 